RESEARCH ARTICLE

\title{
Activated coconut shell charcoal as a component of tissue culture media of Cocos nucifera L.**
}

\author{
S.C. Fernando*, E.S. Santha and D.J.A. Hewarathna \\ Tissue Culture Division, Coconut Research Institute, Bandirippuwa Estate, Lunuwila.
}

Revised: 24 November 2009 ; Accepted: 19 May 2010

\begin{abstract}
In vitro culture media of Cocos nucifera L. (coconut) requires a guaranteed source of activated charcoal with consistent characteristics for reliable results. Activated coconut shell charcoal (ACSC) was tested as a component of the media since a continuous supply of a particular type of activated charcoal with the same origin and characteristics was guaranteed by the manufacturer. Immature zygotic embryos of coconut (variety Sri Lanka Tall) were cultured in basal medium supplemented with two different types of ACSC (A and B) (Haycarb PLC) and BDH charcoal (control).The optimum 2,4 dichlorophenoxyacetic acid (2,4-D) levels to be used with different activated charcoal types were also assessed by culturing of explants and HPLC. The more suitable ACSC type was further tested by culturing plumule explants of coconut. The study revealed that in the presence of suitable concentrations of 2,4-D, media with both ACSC types could produce calli at frequencies comparable to that of the control. Considering the production of calli and mixing qualities of activated charcoal with the medium, ACSC-B was selected as the better ACSC type for coconut callogenesis. In the presence of $175.0 \mu \mathrm{M}$ 2,4-D, the selected ACSC-B induced callusing in 63 and $65 \%$ of immature zygotic embryos and plumules while the control produced 63 and $70 \%$ callusing in respective tissues.
\end{abstract}

Keywords: Activated coconut shell charcoal, callogenesis, Cocos nucifera L., tissue culture.

\section{INTRODUCTION}

Activated charcoal is an essential component of many plant tissue culture media. It prevents browning of cultured tissues and media by adsorption of toxic compounds like polyphenols released by cultured tissues ${ }^{1}$.

Coconut (Cocos nucifera L.) is a highly recalcitrant species to in vitro culture. The presence of an auxin, especially 2,4-dichlorophenoxyaceticacid $(2,4-\mathrm{D})$ is necessary for induction of callus in coconut tissues. Reduction in 2,4-D concentration and application of cytokinin is required for somatic embryogenesis and plant regeneration ${ }^{2,3}$. Alternatively, abscisic acid (ABA) has been successfully used for somatic embryogenesis and plant regeneration ${ }^{4}$. The presence of activated charcoal in the culture medium is critical throughout the tissue culture process. Although activated charcoal is added to remove toxic compounds, it also adsorbs hormones, specially 2,4-D, 6- benzylaminopurine (BAP) ${ }^{5}$ and $\mathrm{ABA}^{6}$ which results in undefined culture conditions.

Different types of activated charcoal are available in the market and their adsorption properties vary with the source, method of preparation/ activation and particle size. Therefore, the use of different types of activated charcoal in the medium results in variations in plant growth regulator levels. This is a major setback in developing a reliable clonal propagation protocol for coconut. The use of one particular type of charcoal throughout an experiment was thought to be the solution. However, a significant variation among product lots has been reported for common commercial grade activated charcoal $^{7}$.

The development of a charcoal-free medium is an alternative to this problem. Even though it was possible to induce callus in coconut tissues in charcoal-free medium, somatic embryogenesis and plant regeneration from calli initiated in charcoal-free media have been retarded ${ }^{8,9}$. Therefore, the use of activated charcoal in coconut tissue culture medium is essential.

Various attempts have been made to overcome the limitations of the use of activated charcoal in the culture

\footnotetext{
${ }^{*}$ Corresponding author (shyamafernando2003@yahoo.com)

** Part of this work was orally presented at the SLAAS Annual Sessions in 2008 and the abstract of same was published.
} 
media of different plant species $^{7,10,11}$. Testing 2,4-D adsorption by activated charcoal using High Performance Liquid Chromatography (HPLC) ${ }^{10}$ and adjusting the 2,4-D level added to the medium accordingly is practised by various coconut tissue culture research groups. Toering and Pullman ${ }^{11}$ have developed a mathematical model to calculate free 2,4-D in Pinus taeda L. (loblolly pine) medium containing activated charcoal. A method to control freely available plant growth regulator levels by adjusting the mass of different activated charcoal types in the medium [based on the ratio of specific total pore volume or Brunauer, Emmett and Teller (BET) specific surface areas of the carbons] was developed by Van Winkle and Pullman?.

The mathematical model of Toering and Pullman ${ }^{11}$ does not consider variations in adsorption capacities of different activated charcoal types used, whereas the method of Van Winkle and Pullman ${ }^{7}$ does not consider the differences in pore size distribution. Those facts limit the direct use of such mathematical methods for optimizing culture media for coconut, which is very sensitive to plant growth regulator levels in the medium. Therefore, cocount tissue cultures need a guaranteed source of activated charcoal with consistent characteristics.

Activated coconut shell charcoal (ACSC) is a potential candidate, as the continuous supply of a particular type of activated charcoal with the same origin and characteristics can be guaranteed by the manufacturer. Therefore, the objective of this study was to assess the feasibility of using ACSC in coconut tissue culture media. ACSC is not availale under trade names like Sigma and BDH and the source of charcoal is not specified in catalogue descriptions. Therefore, this is the first report on the use of ACSC in any plant tissue culture medium.

\section{METHODS AND MATERIALS}

Experimental material: Immature $(9$ months postanthesis) and mature (12 months post-anthesis) coconuts from variety Sri Lanka Tall were used to obtain explants.

Two types of ACSC (A \& B) were provided by Haycarb PLC. Activated charcoal from BDH Laboratory Supplies (England) (BDH Catalogue number 33033) was used as the control. In order to control the moisture content of activated charcoal samples, prior to use, they were oven dried for $1 \mathrm{~h}$ at $150^{\circ} \mathrm{C}$ and kept in desiccators.

Immature zygotic embryo culture: Dehusked immature nuts were washed in a mild detergent solution (Teepol) and immature zygotic embryos were excised aseptically under a laminar flow hood. The embryos were cultured in basal medium $72^{2}$ supplemented with varying levels $(100.0-275.0 \mu \mathrm{M})$ of 2,4-D (Sigma D 7299$), 0.25 \%$ $(\mathrm{w} / \mathrm{v})$ phytagel and $0.1 \%(\mathrm{w} / \mathrm{v})$ ACSC-A (surface area $875 \mathrm{~m}^{2} \mathrm{~g}^{-1}$ ) or ACSC-B (surface area $1500 \mathrm{~m}^{2} \mathrm{~g}^{-1}$ ). Since dried activated charcoal samples were used for culture media preparation for the first time, the immature zygotic embryos were cultured in basal medium 72 supplemented with varying levels $(175.0-275.0 \mu \mathrm{M})$ of 2,4-D and $0.1 \%$ $(\mathrm{w} / \mathrm{v})$ activated charcoal BDH (surface area $1000 \mathrm{~m}^{2} \mathrm{~g}^{-1}$ ) to determine the optimum 2,4-D level as the control. Mixing qualities of ACSC-A and ACSC-B was also observed when preparing the culture media. Cultures were maintained at $28 \pm 1{ }^{\circ} \mathrm{C}$ in darkness for $10 \mathrm{wks}$.

The number of explants producing calli was recorded at the end of 10 wks. The calli were grouped according to the size (diameter $<5.0 \mathrm{~mm}$ and $\geq 5.0 \mathrm{~mm}$ ) and callus morphology was noted.

Determination of the suitability of ACSC-B for plumule culture: Mature zygotic embryos were sterilized in 3.0\% (v/v) Clorox [Sodium hypochlorite 5.25\%, Chlorox (Malaysia) Sdn. Bhd.,] for 5 min and rinsed 5 times with sterile distilled water. Plumules were excised under a dissecting microscope, crushed with a scalpel and cultured in basal medium 72 supplemented with $175.0 \mu \mathrm{M} 2,4-\mathrm{D}$ and $0.1 \%(\mathrm{w} / \mathrm{v})$ ACSC-B (the medium selected from the results of previous experiment) to further test the suitability of ACSC-B type for coconut tissue culture. From the results of the previous experiment, $225.0 \mu \mathrm{M}$ 2,4-D was selected as the control to use with $0.1 \%(\mathrm{w} / \mathrm{v})$ $\mathrm{BDH}$ charcoal. Cultures were maintained at $28 \pm 1^{\circ} \mathrm{C}$ in darkness for $10 \mathrm{wks}$. The number of explants producing calli was recorded at the end of 10 wks.

Analysis of free 2,4-D in the medium: Culture media containing different combinations of 2,4-D and activated charcoal types [BDH (control) and ACSC-A and ACSC-B] were prepared in liquid form. After $7 \mathrm{~d}$ of preparation, the solutions were filtered $(0.2 \mu \mathrm{m})$ to remove charcoal and individual solutions were analyzed.

The samples were analyzed by HPLC (Hewlet Packard 1100) equipped with a variable wave length detector allowing monitoring at $236 \mathrm{~nm}$. Separation was achieved using a reversed phase column $\mathrm{C} 18$ Lichrocart 250-4 with gradient elution. The mobile phase consisted of HPLC grade methanol / acetonitrile (1:1) and $5.0 \mathrm{mM}$ $\mathrm{NaH}_{2} \mathrm{PO}_{4} / 100.0 \mu \mathrm{L}$ acetic acid buffer (pH 7.0). At a flow rate of $0.5 \mathrm{~mL} \mathrm{~min}^{-1}, 2,4-\mathrm{D}$ was eluted after $9 \mathrm{~min}$.

Data collection and statistical analysis: The experimental design was a completely randomized design. The 
experiments on immature zygotic embryo and plumule culture were repeated at least twice with 10-15 explants per treatment. Difference between treatments was assessed using logistic regression analysis in CATMOD procedure in SAS software. Mean separation was done with contrasts of maximum likelihood estimates.

\section{RESULTS AND DISCUSSION}

\section{Immature zygotic embryo culture}

Among the various coconut explants used for clonal propagation, immature zygotic embryos are considered as the model to test culture conditions due to its ability to produce calli consistently at higher frequencies under suitable conditions ${ }^{2}$. Previous studies have shown that the optimum 2,4-D level used with activated charcoal $(\mathrm{BDH})$ varied $(50.0-150.0 \mu \mathrm{M})$ from one pack to the other and within a pack with time of storage ${ }^{12}$. The change in moisture content during storage was identified as a possible cause. Thus, in this study, oven dried activated charcoal samples were used for consistent results. The use of dried activated charcoal increased the actual amount of charcoal present in medium. As a result, explants cultured in media containing previously used 2,4-D levels $(50.0-150.0 \mu \mathrm{M})$ did not produce callus (data not shown). Callusing recorded in media containing 175.0-275.0 $\mu \mathrm{M} 2$,4-D did not vary significantly. It might be due to the highly heterogeneous nature of explants used in the study. Therefore, $225.0 \mu \mathrm{M} 2,4-\mathrm{D}$, the lowest concentration of 2,4-D at which the highest number of calli of diameter $\geq 5.0 \mathrm{~mm}$ was obtained, was selected as the control for culturing immature zygotic embryos of coconut in the presence of activated charcoal $\mathrm{BDH}$ (Table 1).

When ranges of 2,4-D were tested in combination with ACSC-A and ACSC-B (100.0-200.0 and 150.00$250.0 \mu \mathrm{M}$ respectively), all tested combinations produced

Table 1: Effect of 2,4-D level on callogenesis in immature zygotic embryos of coconut in the presence of $0.1 \%(\mathrm{w} / \mathrm{v})$ oven-dried BDH (control) charcoal

\begin{tabular}{lcc}
\hline $\begin{array}{l}2,4-\mathrm{D} \text { level } \\
(\mu \mathrm{M})\end{array}$ & $\begin{array}{c}\text { Callusing } \\
(\%)\end{array}$ & $\begin{array}{c}\text { Callus size } \\
(\% \text { of callus with } \\
\text { a diameter } \geq 5 \mathrm{~mm})\end{array}$ \\
\hline 175.0 & 45.0 & 90.0 \\
200.0 & 63.0 & 80.0 \\
225.0 & 63.0 & 94.0 \\
250.0 & 63.0 & 94.0 \\
275.0 & 45.0 & 67.0 \\
Significance at $5 \%$ & $\mathrm{NS}$ & $\mathrm{NS}$ \\
\hline
\end{tabular}

NS $=$ Not significant varying percentages of calli that are not significantly different. It might be due to the heterogeneous nature of explants used. However, based on the highest callusing percentage, callus size and production of highly convoluted translucent calli, 2,4-D: activated charcoal combinations of $125.0 \mu \mathrm{M} 2,4-\mathrm{D}$ with ACSC-A and $175.0 \mu \mathrm{M} 2,4-\mathrm{D}$ with ACSC-B were selected as the suitable combinations. The callusing percentages of the selected combinations were also comparable to those of the control (Table 2).

However, when preparing media, particles of ACSC-A precipitated more easily than ACSC-B. Thus ACSC-A showed poor mixing qualities which might cause inconsistent results from cultured tissues unless during preparations, the media are frequently mixed before they are solidified. Therefore, ACSC-B can be considered as the more suitable type of ACSC to be used in coconut tissue culture media.

\section{Analysis of free 2,4-D in the medium}

Testing a range of 2,4-D levels and activated charcoal types requires a large number of nuts to obtain explants which is costly, laborious and time consuming. Therefore, attempts were made to develop an analytical method for selecting suitable activated charcoal: 2,4-D level combinations. An estimation of available 2,4-D in the culture medium was done using HPLC analysis. This technique has been used previously to identify free 2,4-D in charcoal containing media ${ }^{7,10}$. Adsorption of 2,4-D by activated charcoal is controlled by many factors such as physical status of medium, temperature and various culture media components ${ }^{11}$. The results revealed that the levels of free 2,4-D in the three media combinations (liquid form) ( $225.0 \mu \mathrm{M} 2,4-\mathrm{D}+\mathrm{BDH}, 125.0 \mu \mathrm{M} 2,4-\mathrm{D}$ + ACSC-A and $175.0 \mu \mathrm{M}$ 2,4-D + ACSC-B) which showed comparable callusing was more or less similar (2.47, 1.69 and $2.11 \mu \mathrm{M}$ respectively) (Table 3 ). The results show that despite the higher levels of 2,4-D added to the culture media, very low levels are available as active 2,4-D and confirm the high rate of adsorption of 2,4-D by activated charcoal.

\section{Determination of the suitability of ACSC-B for plumule culture}

The effects of media containing activated charcoal types ACSC-B and BDH (control) on culturing of coconut plumules were compared in order to determine the suitability of ACSC-B for culturing of various coconut tissues. Results showed 65 and $70 \%$ callusing in media with ACSC-B and BDH activated charcoal indicating that ACSC-B can be used effectively for callus induction in coconut plumules as well. 
Table 2: Effect of ACSC type: 2,4-D level combinations on callogenesis in immature zygotic embryos of coconut

\begin{tabular}{lccc}
\hline $\begin{array}{l}\text { Activated charcoal } \\
\text { type }\end{array}$ & $\begin{array}{c}2,4-\mathrm{D} \text { level } \\
(\mu \mathrm{M})\end{array}$ & $\begin{array}{c}\text { Callusing } \\
(\%)\end{array}$ & $\begin{array}{c}\text { Callus size } \\
(\% \text { of callus with a } \\
\text { diameter } \geq 5 \mathrm{~mm})\end{array}$ \\
\hline \multirow{2}{*}{ ACSC-A } & 100.0 & 40.0 & 100.0 \\
& 125.0 & 59.0 & 100.0 \\
& 150.0 & 59.0 & 90.0 \\
& 175.0 & na & na \\
& 200.0 & 56.0 & 82.0 \\
ACSC-B & 150.0 & 61.0 & 82.0 \\
& 175.0 & 63.0 & 100.0 \\
& 200.0 & 47.0 & 100.0 \\
& 225.0 & 47.0 & 89.0 \\
BDH (Control) & 250.0 & 53.0 & 80.0 \\
Significance at 5\% & 225.0 & 63.0 & 94.0 \\
\hline
\end{tabular}

$\mathrm{NS}=$ Not significant; na $=$ Not available due to contamination of many replicates

Table 3: Free 2,4-D levels in culture media supplemented with various combinations of 2,4-D and activated charcoal

\begin{tabular}{lcc}
\hline Activated charcoal type & $\begin{array}{c}\text { 2,4-D level added } \\
\text { to medium }(\mu \mathrm{M})\end{array}$ & $\begin{array}{c}\text { Free 2,4-D level available } \\
\text { in medium }(\mu \mathrm{M})\end{array}$ \\
\hline \multirow{2}{*}{ ACSC-A } & 125.0 & 2.47 \\
& 150.0 & 3.25 \\
& 175.0 & 4.98 \\
& 200.0 & 6.17 \\
ACSC-B & 175.0 & 1.69 \\
& 200.0 & 2.61 \\
& 225.0 & 4.09 \\
BDH (control) & 250.0 & 4.50 \\
& 225.0 & 2.11 \\
& 250.0 & 3.74 \\
& 275.0 & 5.08 \\
\hline
\end{tabular}

\section{CONCLUSION}

Activated charcoal is a critical culture media component which can create variable culture conditions depending on the type, production batch, other media components and method of media preparation. Due to the highly recalcitrant nature of coconut, consistent culture conditions are necessary for reliable results. Selection of a reliable activated charcoal type is critical in this regard.
This study enabled the selection of a suitable type of ACSC for coconut tissue culture. This was confirmed by culturing of immature zygotic embryos and plumule explants of coconut.

\section{Acknowledgement}

Authors kindly acknowledge Haycarb PLC for providing activated coconut shell charcoal samples, The staff of the Coconut Research Institute, Miss Mithila Jayasundara for assistance in HPLC analysis, Mrs. Pramuditha 
Waidyarathne for assistance in statistical analysis and Dr. Kaushalya Weerakoon for reviewing the manuscript is also acknowledged.

\section{References}

1. Pan M.J. \& van Staden J. (1998). The use of charcoal in in vitro culture- a review. Plant Growth Regulation 26(3): 55-163.

2. Karunaratne S. \& Periyapperuma L.K. (1989). Culture of immature embryos of coconut, Cocos nucifera L. callus proliferation and somatic embryogenesis. Plant Science $62(2): 247-253$.

3. Verdeil J.L. \& Buffard-Morel J. (1995). Somatic embryogenesis in coconut (Cocos nucifera L.). In: Somatic Embryogenesis and Synthetic Seeds I, Biotechnology in Agriculture and Forestry (Ed.Y.P.S. Bajaj). pp. 299-317, Spring-Verlag, Berlin.

4. Fernando S.C. \& Gamage C.K.A. (2000). Abscisic acidinduced somatic embryogenesis in immature embryo explants of coconut (Cocos nucifera L.). Plant Science 151(2):193-198.

5. Ebert A., Taylor F. \& Blake J. (1993). Changes of 6 benzylaminopurine and 2,4 dichlorophenoxyacetic acid concentrations in plant tissue culture media in the presence of activated charcoal. Plant Cell, Tissue \& Organ Culture 33 (2):157-162.

6. Pullman G.S., Gupta P.K., Timmis R., Carpenter C., Kreitinger M. \& Welty E. (2005). Improved Norway spruce somatic embryo development through the use of abscisic acid combined with activated carbon. Plant Cell
Reports 24(5):271-279.

7. Van Winkle S.C. \& Pullman G.S. (2005). Achieving desired plant growth regulator levels in liquid plant tissue culture media that include activated carbon. Plant Cell Reports 24(4):201-208.

8. Diyasena R.A.C.N.M. (1998). Development of a charcoalfree protocol for callogenesis and somatic embryogenesis in immature embryo explants of coconut (Cocos nucifera L.). M.Sc Thesis, University of Colombo, Colombo.

9. Adkins S.W., Samosir Y.M.S. \& Godwin I.D. (1990). Control of environment conditions and the use of polyamines can optimize the conditions for the initiation and proliferation of coconut somatic embryogenesis. In: Current Advances in Coconut Biotechnology (Eds. C. Oropeza, J.L. Verdeil, G.R. Ashburner, R. Cardena \& J.M. Santamaria) pp. 321-340, Kluwer Academic Publishers, Dordrecht, The Netherlands.

10. Verdeil J.L., Hornung R., Jacobsen H.J., Rillo E., Oropeza C., Bourdeix R., N'cho Y.P., Hocher V., Hamon S. \& Sangare A. (1999). Recent progress on coconut micropropagation through a joined effort involving different countries. In: Current Advances in Coconut Biotechnology (Eds. C. Oropeza, J.L.Verdeil, G.R. Ashburner, R. Cardena \& J.M. Santamaria) pp. 391-405, Kluwer Academic Publishers, Dordrecht, The Netherlands.

11. Toering A. \& Pullman G.S. (2005). Modeling available 2,4-dichlorophenoxyacetic acid in a tissue culture medium containing activated carbon. Plant Cell, Tissue \& Organ Culture 82(2): 179-188.

12. Weerakoon L.K. (2007). Report of the tissue culture division, Annual Report, Coconut Research Institute, Bandirippuwa Estate, Lunuwila. 